\title{
The Influence of Shearing Stress on Thermal Homeostasis and Performance of Barki Ewes in the North Western Desert of Egypt
}

\author{
E. A. Taha
}

Department of Wool Production \& Technology, Desert Research Centre, Cairo, Egypt

\begin{abstract}
Twenty four adult non-pregnant; non-lactating Barki ewes, aged 3 to 4 years with initial body weight of $(35.75 \pm 1.15)(\mathrm{kg})$ were randomly divided to two groups $(\mathrm{n}=12)$. Ambient temperature $(A T)$ and relative humidity $(\mathrm{RH})$ were recorded along the trail and temperature humidity index (THI) was estimated. The first group was kept as a control unshorn group while the second group was shorn to inspect the effects of shearing on body weight, physiological responses and thermal homeostasis of shorn ewes. Animals were weighed on days 0, 15,30 and 45. Rectal temperature $(R T)$, skin temperature $(S T)$ and respiration frequency $(R R)$ were measured on days $0,1,3,15,30$ and 45 andThermal gradients (RT-ST) and (ST-AT) were assessed.

Irrespective of the lost fleece weight on day 0, shorn ewes continued to lose more of their weights till day 15 then they started to regain their body weight. Shearing reduced $(P<0.05) R T$ and $R R$ of shorn ewes to lower values than their control mates. It also declined ST of shorn ewes $(P>0.05)$ compared with the control group. Differences in (RT-ST) and ambient (ST-AT) between groups were insignificant. Shorn ewes retained lower values of RT, ST and RR than the controls during the experiment.
\end{abstract}

Results indicated the capacity of shorn Barki ewes to maintain their thermoregulation stability by using energy retention mechanisms andto regain body weight. That might indicate a temporal moderate effect of shearing if it was under mild climatic conditions.

Keywords-Barki, Ewes, Homeostasis, Shearing, Stress

\section{INTRODUCTION}

Wool fleece helps sheep maintaining its thermal balance under hot and cold climates as it resist thermal exchange between sheep body and the ambient atmosphere. Consequently, it helps in maintaining core temperature, skin temperature and respiration rate of sheep [21].

Shearing is a routine work in the different sheep rearing systems to harvest wool. In extreme environments, shearing modifies the magnitude and direction of heat exchange and shifts the thermo-neutral zone that impeding the maintenance of homeothermy [4].

The physiological responses of sheep differ according to the surrounding climatic conditions of the shearing season [26], [27] and [28]. Irrespective of season, shearing is associated with some degree of thermal stress that might affect the welfare and productivity of sheep [4] by altering its thermal balance[21] and shifting adaptive thermogenesis via nervous responses to readjust energy saving mechanisms related to climatic adaptability [2], [8] and [20].

Traditionally, this process takes place during spring to avoid the negative effects of climatic extremes during hot and cold seasons. However, spring shorn sheep may be exposed to a wide range of climatic variations due to the fluctuations of ambient temperature and relative humidity rather than the observed differences between day and night temperatures during this season. Even under mild climates, shearing corrupts heat balance mechanisms as it makes sheep more reliable to climatic stress after removing its insulating layer, fleece. Therefore, several changes could be expected in rectal temperature, skin temperature and respiration frequency [8], [23] and [27].The impact of shearing as stress stimulus ranges between moderate [11] to effective [12] stressor.

The current study aimed to evaluate the effects of shearing stress on body weight, physiological parameters and thermal homeostasis of Barki ewes reared under the 
semi-arid desert conditions of the northwest coastal belt of Egypt.

\section{MATERIALS AND METHODS}

This study was carried out in Maryout Research Station ( $32^{\circ} \mathrm{N}$ Latitude, $35 \mathrm{~km}$ southwest of Alexandria), Desert Research Center, Ministry of Agriculture and Land Reclamation, Egypt. This location represents the semi-arid desert conditions of the northwest coastal belt of Egypt.

\section{1 Meteorological data}

Maximum, minimum and average ambient temperature $\left(\mathrm{AT},{ }^{\circ} \mathrm{C}\right)$ besides relative humidity $(\mathrm{RH}, \%)$ were recorded daily along the experiment by data logger (Gemini. Chichester, UK).The amplitude between the maximum day and minimum night temperatures was calculated by subtraction $\left({ }^{\circ} \mathrm{C}\right)$.Temperature-Humidity Index (THI), as an indicator of thermal comfort of sheep, was calculated according to Casella et al., (2016) as follow:

$\mathrm{THI}=\mathrm{AT}-0.55$ (1- (0.01 RH) (AT-14.5).

Where AT: average ambient temperature $\left({ }^{\circ} \mathrm{C}\right)$ and $\mathrm{RH}$ : relative humidity (\%).

\section{2 Animals and management}

Twenty four adult non-pregnant, non-lactating Barki ewes, aged 3-4 years with average initial body weight of $35.75 \pm$ $1.15 \mathrm{~kg}$ were randomly divided to two equal groups $(n=12)$. All animals were apparently healthy and free of internal and external parasites. The first group was kept unshorn to serve as control while the ewes of the second group were shorn in spring $\left(27^{\text {th }}\right.$ April, 2018). Shearing was conducted manually at the same time for all the shorn ewes and lasted for about 5 minutes for each head. The remained wool after shearing was of average length of $0.5 \mathrm{~cm}$.

Animals were housed in sheltered semi-open pins and fed concentrate feed mixture $(0.5 \mathrm{~kg}$ head- 1 day- 1$)$ consisted of $50 \%$ cottonseed cake, $15 \%$ yellow corn, $18 \%$ wheat bran, $11 \%$ rice polish, $3 \%$ molasses, $2 \%$ limestone and $1 \%$ common salt. The concentrate mixture contained $60 \%$ TDN and 14\% CP. Berseem hay (Trifolium alexandrinum) was offered $a d . L i b .$, drinking access was available twice a day.

\section{3 Live body weight}

Live body weight of the experimental animals was recorded in early morning before feeding and drinking to the nearest $0.1 \mathrm{~kg}$ by digital balance. On the day before shearing (day0), all animals were weighed twice before and after shearing. The weighing process was repeated on days 15,30 and 45 after shearing.

\section{4 Physiological parameters}

Rectal temperature $\left(\mathrm{RT},{ }^{\circ} \mathrm{C}\right)$, skin temperature $\left(\mathrm{ST},{ }^{\circ} \mathrm{C}\right)$ and respiration frequency (breath/minute) were measured on days $0,1,3,15,30$ and 45, thereafter. Rectal temperature (RT) was measured to the nearest $0.1{ }^{\circ} \mathrm{C}$ using a standard clinical thermometer inserted into the rectum. Skin temperature (ST) was taken using a digital thermometer placed over the skin at the mid-side regions of each ewe. Respiration frequency was recorded by counting frequency of flank movements per minute; all required precautions were considered to avoid animal's disturbance.

\section{5 Statistical analysis}

The effects of treatment, time, day and all the possible interactions among the aforementioned factors on the studied parameters were examined by illustrating the experimental animals in factorial design trail. Least square means and standard errors of experimental groups were calculated by using proc. GLM of SAS (2013) program according to [25]. Differences between means were estimated by Duncan multiple tests at confidence level of 0.05 for independent factors and their interactions according to the following statistical model:

The effects of treatment, time, day and all the possible interactions among the aforementioned factors on the studied parameters were examined by illustrating the experimental animals. Least square means and standard errors of experimental groups were calculated by using GLM Proc. of SAS (2013) program. Differences between means were estimated by Duncan multiple tests at confidence level of 0.05 for independent factors and their interactions according to the following statistical model:

$\mathrm{Y}_{\mathrm{ijkl}}=\mu+\mathrm{T}_{\mathrm{i}}+\mathrm{M}_{\mathrm{j}}+\mathrm{D}_{\mathrm{k}}+\left(\mathrm{T}_{\mathrm{i}} \times \mathrm{M}_{\mathrm{j}}\right)+\left(\mathrm{T}_{\mathrm{i}} \times \mathrm{D}_{\mathrm{k}}\right)+$

$$
\left(\mathrm{M}_{\mathrm{j}} \times \mathrm{D}_{\mathrm{k}}\right)+\mathrm{A}_{\mathrm{l}}\left(\mathrm{T}_{\mathrm{i}}\right)+\mathrm{e}_{\mathrm{ijkl}}
$$

Where:

$\mathrm{Y}_{\mathrm{ijk}}$ : Any observation,

$\mu$ :Overall mean,

$\mathrm{T}_{\mathrm{i}}$ :Effect of $\mathrm{i}^{\text {th }}$ treatment $(\mathrm{i}=1-2)$,

$\mathrm{M}_{\mathrm{j}}$ : Effect of $\mathrm{j}^{\text {th }}$ time $(\mathrm{j}=1-2)$,

$D_{k}$ : Effect of $k^{\text {th }}$ day $(k=1-6)$.

$\mathrm{T}_{\mathrm{i}} \times \mathrm{M}_{\mathrm{j}}$ : Effect of interaction between $\mathrm{i}^{\text {th }}$ treatment and $\mathrm{j}^{\text {th }}$ time,

$\mathrm{T}_{\mathrm{i}} \times \mathrm{D}_{\mathrm{k}}$ :Effect of interaction between $\mathrm{i}^{\text {th }}$ treatment and $\mathrm{k}^{\text {th }}$ day,

$M_{j} \times D_{k}$ : Effect of interaction between $j^{\text {th }}$ time and $k^{\text {th }}$ day,

$\mathrm{A}_{\mathrm{l}}\left(\mathrm{T}_{\mathrm{i}}\right)$ : Effect ofeach $\mathrm{1}^{\text {th }}$ animal within $\mathrm{i}^{\text {th }}$ treatment (as error 1). 
$\mathrm{e}_{\mathrm{ijkl}}$ :residual (as error 2).

\section{RESULTS AND DISCUSSION}

\section{1 Meteorological conditions}

Meteorological measurements were summarized in (Fig. 1). Average ambient temperature changed within a narrow range of about $4{ }^{\circ} \mathrm{C}$ where it tended to increase on day 45 to its highest value. In contrast, the amplitude between day and night temperatures declined on days 30 and 45 indicating an increased night temperature in this period. Relative humidity increased gradually by about $2.5 \%$ from day 0 to day 15 and then it increased sharply in day 30 (about 5\%) to reach the highest record at day 45 (72\%). Temperature-humidity index (THI) did not seriously differ along the experiment and were within the comfort zone for sheep as THI values were $<72$ values along the experiment[1].
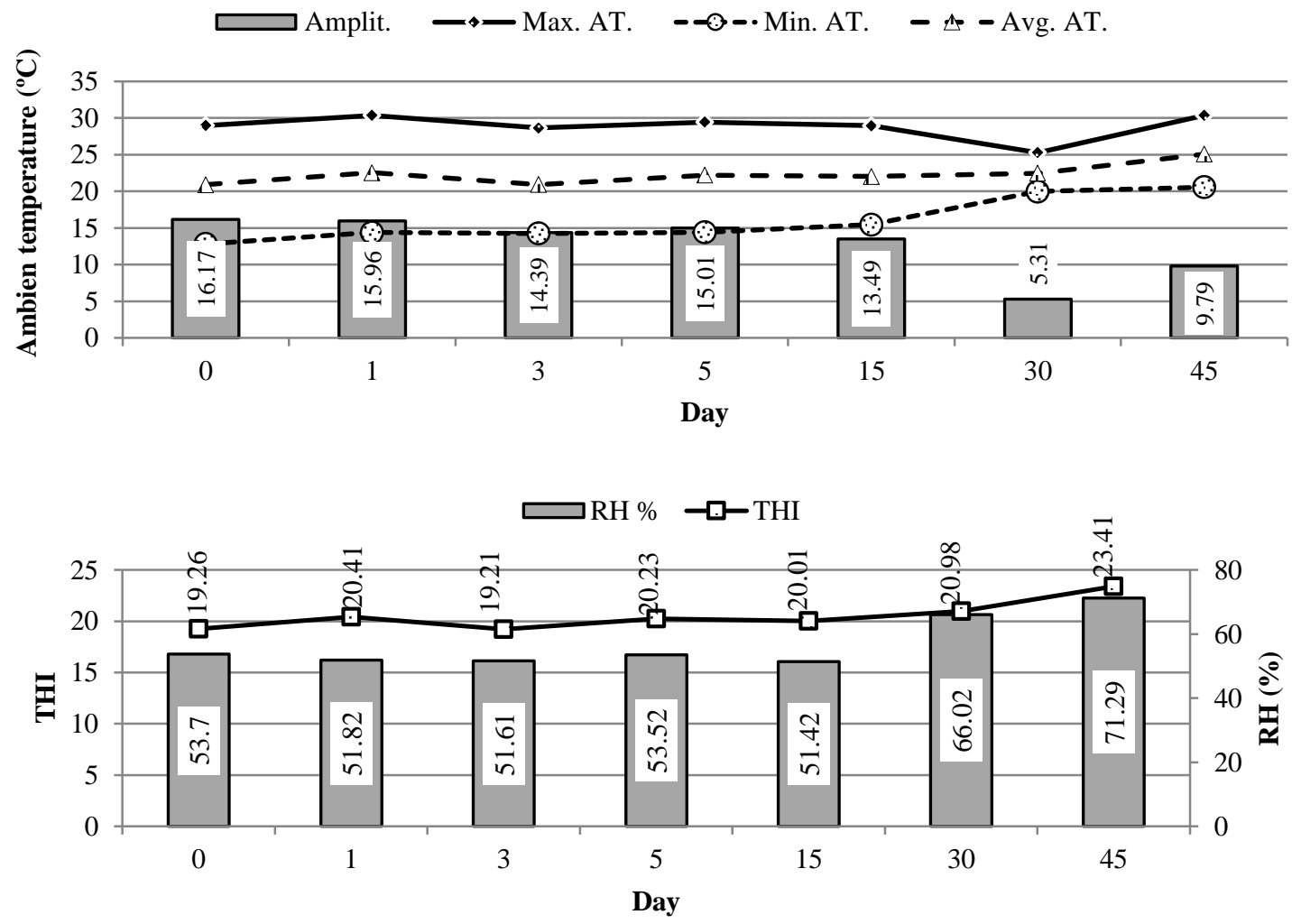

Fig.1: Meteorological data throughout the experiment.

\section{2 Live body weight}

Initial body weight was homogeneous as the difference between groups was insignificant; the corresponding values were $35.87 \pm 1.625$ and $35.62 \pm 1.625 \mathrm{~kg}$ for of control and shorn groups, respectively. Although no significant differences between unshorn and shorn ewes at days 15,30 and 45, body weight of shorn sheep declined after shearing and retained lower values than unshorn ewes till day 45 (Fig. 2).

Rather than the subtracted greasy fleece weight in day 0 $(1.30 \pm 0.141 \mathrm{Kg})$ which equals to the mean fleece weight, shorn group continued to lose more weight till day 15 were they lost $(0.93 \pm 0.138 \mathrm{~kg})$ of their body weight compared with their body weight at day 0 after shearing. Weight loss declined on days 30 and 45to minor magnitudes (0.45 \pm 0.138 and $0.03 \pm 0.138 \mathrm{~kg}$, respectively)(Fig.3) to achieve lower but not significantly differentfinal body weight than their initial body weight and the final body weight of the control group (Table 1).Therefore, Mean body weight of shorn ewes $(34.15 \pm 0.700 \mathrm{~kg})$ was lower $(\mathrm{P}<0.05)$ than that of unshorn ewes $(36.250 .700 \mathrm{~kg}$ ) as they experienced greater body weight fluctuations after fleece removal as shown in Fig. (3). On the other hand, body weight of unshorn ewes increased gradually to end the experiment at higher $(\mathrm{P}>0.05)$ final body weight than its own initial body weight.

The analysis of variance showed significant $(\mathrm{P}<0.01)$ effect of treatment, day and treatment $x$ day interaction on body weight change that lead to the obvious variations between shorn and unshorn ewes in their body weight responses to shearing and the climatic conditions records at each day point. Fleece provides protection against extreme heat exchange between the naked skin and the ambient air to maintain constant body temperature and lower energy 
requirements for thermoregulation [4], [10] and [20]. Therefore, removing the fleece enhances heat dissipation from the body surface to the surrounding environment and shifts the thermoregulatory set point that leading to higher utilization of body reserves to meet the elevated energy requirements[2], [21] and [8]. Regarding the constant nutritional level along the trail, it is logic to expect the body weight loss in shorn ewes. Coincidently, [6] revealed that shorn sheep require more feed intake to maintain their body weight and to compensate the utilized amounts of their body reserves in thermoregulation. Similar results were reported by [27] who revealed that despite the insignificant effect of shearing on body weight of shorn ewes, they still in need to enhanced nutritional levels to maintain their body weight after shearing.

The decreased body weight loss after day 15 indicates the capacity of shorn Barki ewes to regain their body weights.
Previous reports referred body weight regain after shearing to some positive effects of shearing i.e. motivating feed intake [24], elevating feed conversion rates [19] and improving the performance of shorn ewe's [17].However, the stimulatory effect of shearing on body weight gain may presumably occur when the stimulating effect on the appetite is greater than that required to meet the increased demand for heat production [2].Moreover, body weight regain of shorn ewes at days 30 and 45 was associated with higher average AT and lower AT amplitude when they experienced a period of more warmth climate for longer day time (Fig. 1). In accordance, no negative effect of shearing was detected on body weight of heat stressed fat tail Awassi lamsas they did not need to utilize their tissue's energy to produce more metabolic heat [10].

Table 1: Least squares means \pm standard errors of initial body weight (IBW), final body weight (FBW), mean body weight $(M B W)$ and body weight change rate $(B W C)$ in kilograms as affected by shearing.

\begin{tabular}{lllll}
\hline Treatment & IBW & FBW & MBW & BW Change \\
\hline Unshorn & $35.87 \pm 1.618$ & $36.75 \pm 1.634$ & $36.25 \pm 0.706^{\mathrm{a}}$ & $0.87 \pm 1.121^{\mathrm{a}}$ \\
Shorn & $35.62 \pm 1.618$ & $34.29 \pm 1.634$ & $34.15 \pm 0.706^{\mathrm{b}}$ & $-1.33 \pm 1.121^{\mathrm{b}}$ \\
\hline
\end{tabular}

Means with different superscripts in the same column differ significantly $(\mathrm{P}<0.05)$.

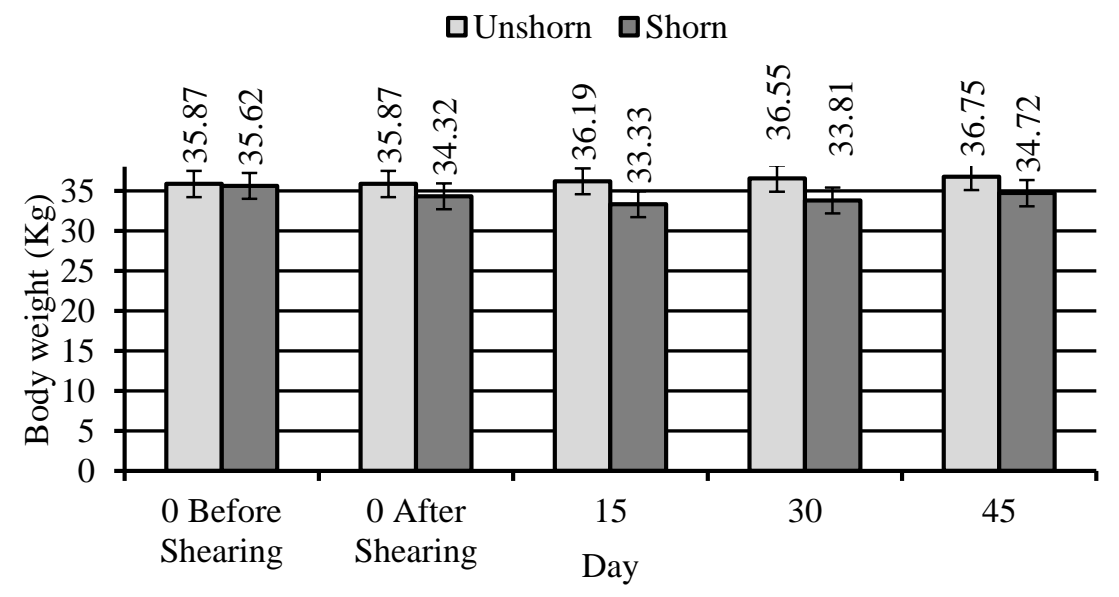

Fig. 2: Body weights of the experimental groups throughout the experiment. 


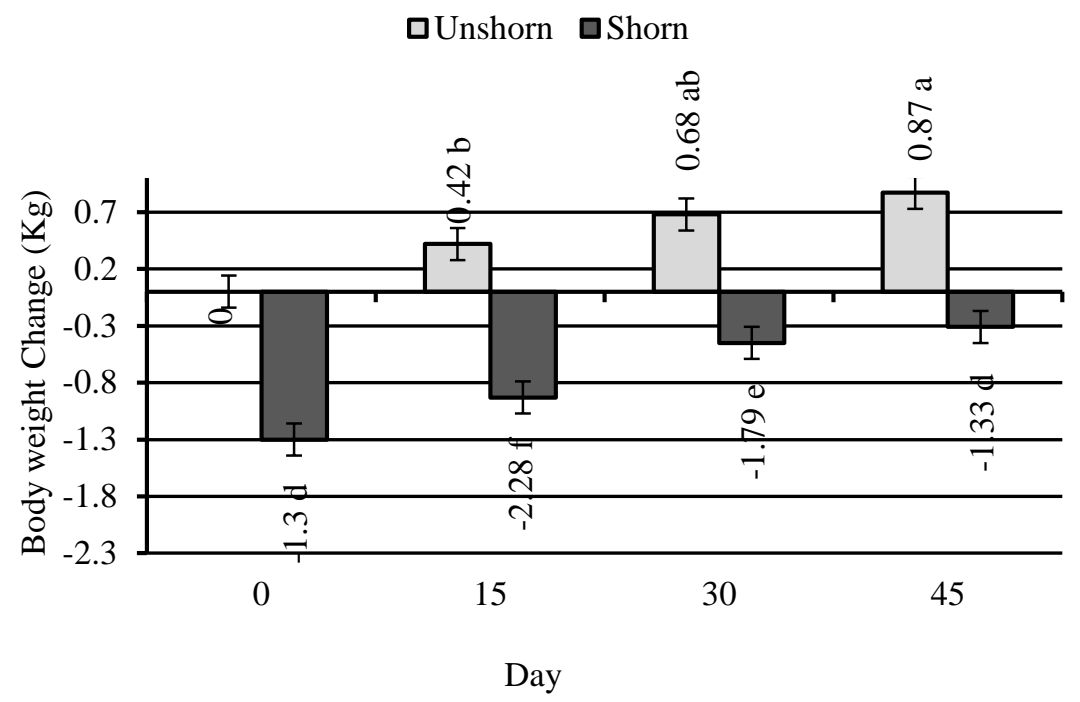

Fig.3: Body weight changes of the experimental groups throughout the experiment.

\section{3 Physiological responses}

On the day before shearing (day 0), no significant differences in rectal temperature, skin temperature and respiration rate were detected between unshorn and shorn ewes, confirming the homogeneity of the sheep population. After shearing, shorn ewes recorded lower values of RT $(\mathrm{P}<0.01)$, ST $(\mathrm{P}>0.05)$ and $\mathrm{RR}(\mathrm{P}<0.01)$ than their unshorn mates.The effects of time, day and all interactions were highly significant on the studied physiological traits.

Shorn ewes had lower $(\mathrm{P}<0.05)$ RT than unshorn ones at both monitoring times $(39.42 \pm 0.779$ and $39.80 \pm 0.784$ ${ }^{\circ} \mathrm{C}$, respectively). In addition, It also recorded lower $(\mathrm{P}<0.05) \mathrm{RT}$ at 8:00 am $\left(39.25 \pm 0.110{ }^{\circ} \mathrm{C}\right)$ than at 2:00 pm $\left(39.85 \pm 0.106{ }^{\circ} \mathrm{C}\right)($ Table 3$)$.

On day1, shearing declined $(\mathrm{P}<0.05) \mathrm{RT}$ of shorn ewes to lower value than that of unshorn ewes at both time points. The corresponding values were 39.66 vs. $39.75^{\circ} \mathrm{Cat}$ 8:00 am and 39.12 vs. $40.55{ }^{\circ} \mathrm{C}$ at2:00 pm.Moreover, the recorded RT values of shorn sheep were lower $(\mathrm{P}<0.05)$ than the initial values recorded in Day 0. From day 3 upward to the end of the trail, shorn ewes retained lower RT degrees than the unshorn ones at both time points. RT presents the net result of heat production by the animal and heat exchange to the environment [16]. Therefore the results may emphasis lower metabolic activity in shorn than in unshorn ewes at both time points. [21] reportedsudden temporal reduction in RT that occurs after shearing. They considered this reductionas an effective stimulator to readjust the homoeothermic set point to new level that meet the induced changes in metabolic requirements. Consequently, shearing modifies nervous control mechanisms that collaborate in readjusting the thermoregulatory responses [4]. Physically,bylowering its metabolic rate shorn ewes succeeded indecreasing its core to peripheral thermal gradient toimpede heat dissipation from the body tissues to the periphery andminimizes heat dissipation to surrounding environment [3].

Shearing declined ST at morning time when shorn ewes had lower $(\mathrm{P}<0.05) \mathrm{ST}\left(36.08 \pm 0.151{ }^{\circ} \mathrm{C}\right)$ than unshorn ewes $\left(36.69 \pm 0.151{ }^{\circ} \mathrm{C}\right)$ while the difference between groups was insignificant at afternoon time. This may explain the insignificant between groups difference in overall ST. Shearing effect on ST extended to longer time compared with the effect on RT as it continued up to day 3though it was limited in morning time where shorn ewes had lower $(\mathrm{P}<0.05) \mathrm{ST}$ than unshorn mates at 8:00 pm. The corresponding values were 36.11 vs. $36.82{ }^{\circ} \mathrm{C}$ on day 1 and 35.45 vs. $36.33{ }^{\circ}$ Con day 3(Fig. 4).Shearing in mild and cold climates dramatically reduce body temperature due to the inefficient peripheral insulation of shorn sheep [2]. Lower ST stimulates the subcutaneous cold receptors to modify the metabolic level by decline ST [12]. In addition, changes in ST reflect a complex interaction of several factors that affect the metabolism [15].

Respiration frequency (Breath/minute) was slower $(\mathrm{P}<0.05)$ in shorn $(38.96 \pm 0.394)$ than in unshorn sheep $(40.55 \pm 0.412)$. Concerning the effect of time, the difference between shorn and unshorn sheep was significant at 8:00 am where RR was lower $(\mathrm{P}<0.05)$ in in shorn $(37.67 \pm 0.545)$ than that of unshorn sheep $(39.59 \pm$ $0.569)$. On the hand the difference between groups was insignificant at 2:00 pm. This may indicate more sensitivity of shorn ewes to the colder time of the day as they reduced 
their RR to minimize heat loss via respiratory evaporation.Coincidently, [26] reported a significant decrease in RR of shorn sheep at morning compared with afternoon time. According to [7], RR reduction in sheep is a thermoregulatory adjustment to the environmental temperature directed at heat conservation. Therefore, shorn ewes reduced theirRR at morning time toreducebody heat loss via respiratory evaporation during the cold time of the day. In contrast, both groupsincreased RR at afternoon to facilitate heat dissipationby increasing respiratory evaporation[9] and [4].

Theresults were in accordance with those of [22] on ewes, [26] on rams and [19] on lambs.According to [18], pulmonary ventilation control aims to balance metabolic needs with homoeothermic requirements.

On day 30, there were observed elevations in RT, ST and RR of both groups that coincided with the lower amplitude between maximum and minimum ambient temperature on this day (Fig 4). This may indicate to effect of exposure to longer time of higher ambient temperature during the day. Generally, the daily RT, ST and RRvalues at both time points coincided with the changes inrecorded ambient temperature and the amplitude between the maximum and minimum temperatures toward the end of the experiment (Fig.1). In accordance,[4],[19] and [26] indicated that shearing alters the circadian and diurnal rhythmsofRT, ST and RR as adaptive responses to modifying the metabolic activity of the shorn sheep to accommodate the shifted homoeothermic set point after shearing. Reducing the metabolic activity leads to conserve body reserves of being utilizedin generating extra heat that could be easily dissipate after fleece removal[5] and may end to body weight loss [6].

In coincidence with [14], by lowering RT and ST shorn ewes succeeded in maintaining their peripheral temperature near to the ambient temperature degrees. Consequently, differences in (RT-ST) and (ST-AT) gradients between unshorn and shorn ewes were insignificant (Table 3). On day1 afternoon, shorn ewes recorded lower $(\mathrm{P}<0.05) \mathrm{RT}$ ST gradient than unshorn ones due to the obvious reduction in ST recorded on this day at 2:00 pm (Fig. 4 \& 5). Amplitude of RT-ST gradient at 8:00 am was about the double of that pointed at 2:00 pm (Table 3). It means that shorn ewes were largely exposed to body heat loss during the cold night and early morning hours especially if (STAT) gradient was taken in account. At 8:00 am (ST-AT) gradient was about two folds of its 2:00 pm value. However, the differences between shorn and unshorn ewes were insignificant at any of the monitoring days. This may emphasis that the decline in ST which took place after shearing was an advantageous to the shorn ewes in order to reduce body heat loss to the cooler surrounding environment. At 2:00 pm, when the ambient temperature elevates, the differences between shorn and unshorn ewes in RT-ST gradient were less announced compared with those recorded at 8:00 am (Fig. 5). This may be due to larger amount of body heat loss via respiratory ventilation in shorn ewes at 2:00 pm as mentioned previously (Fig. 4).

Table 2: Least squares means \pm standard errors of rectal temperature $(R T)$, skin temperature $(S T)$ and respiration rate $(R R)$ as affected by shearing and time points.

\begin{tabular}{lllll}
\hline & & $8: 00 \mathrm{am}$ & $2: 00 \mathrm{pm}$ & Overall \\
\hline \multirow{2}{*}{$\mathrm{RT}\left({ }^{\circ} \mathrm{C}\right)$} & Unshorn & $39.62 \pm 0.107^{\mathrm{b}}$ & $39.99 \pm 0.111^{\mathrm{a}}$ & $39.80 \pm 0.784^{\mathrm{A}}$ \\
& Shorn & $39.25 \pm 0.110^{\mathrm{c}}$ & $39.58 \pm 0.106^{\mathrm{b}}$ & $39.42 \pm 0.779^{\mathrm{B}}$ \\
& Overall & $39.44 \pm 0.078^{\mathrm{b}}$ & $38.78 \pm 0.078^{\mathrm{a}}$ & \\
\hline $\mathrm{ST}\left({ }^{\circ} \mathrm{C}\right)$ & Unshorn & $36.69 \pm 0.147^{\mathrm{b}}$ & $38.42 \pm 0.152^{\mathrm{a}}$ & $37.52 \pm 0.133$ \\
& Shorn & $36.08 \pm 0.151^{\mathrm{c}}$ & $38.40 \pm 0.146^{\mathrm{a}}$ & $37.28 \pm 0.132$ \\
& Overall & $36.39 \pm 0.106^{\mathrm{b}}$ & $38.41 \pm 0.106^{\mathrm{a}}$ & \\
$\mathrm{RR}$ & Unshorn & $39.59 \pm 0.569^{\mathrm{c}}$ & $41.51 \pm 0.569^{\mathrm{a}}$ & $40.55 \pm 0.412^{\mathrm{A}}$ \\
$($ Breath/minute $)$ & Shorn & $37.67 \pm 0.545^{\mathrm{b}}$ & $40.25 \pm 0.545^{\mathrm{ab}}$ & $38.96 \pm 0.394^{\mathrm{B}}$ \\
\hline
\end{tabular}

Means with different lowercase superscripts in the same row and uppercase superscripts in the same column differ significantly $(\mathrm{P}<0.05)$. 
Depending on the changes in physiological responses induced by shearing, it could be concluded that shorn Barki ewes may have the capacity to regulate their metabolic activities when experience mild cold exposure by heat retention mechanisms rather than substantial increased heat production to lower body weight reduction due to utilization of their energy reserves. Therefore, it may be of importance to retard shearing to period of more warmth climate to avoid any negative effect on the body weight of the sheep herds particularly under limited levels of nutrition.

\section{ACKNOWLEDGEMENTS}

Thanks are due to Dr. Samir M. Alsheikh, Prof. of animal husbandry, Desert Research Center and Dr. Ahmed I. Nasr, Associate Prof. of leather tanning tech., Desert Research Center; for their valuable aids in data analysis and manuscript preparations.
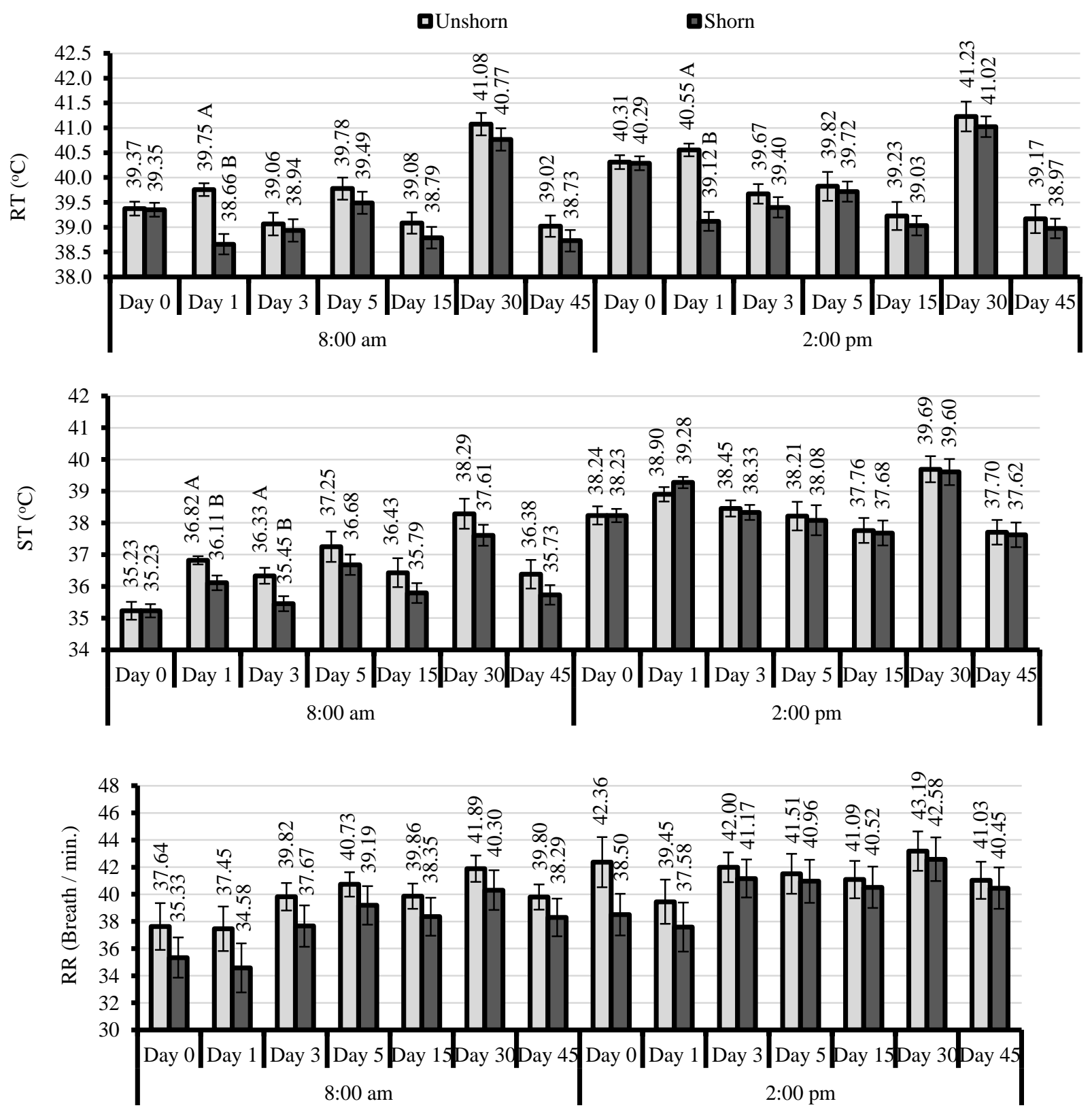

Fig.4: Rectal temperature, Skin temperature and respiration frequency of the experimental groups at 8:00 am and 2:00 pm time points throughout the experiment. 
International Journal of Environment, Agriculture and Biotechnology, 5(2)

Mar-Apr, 2020 / Available: https://ijeab.com/

Table 3: Least squares means \pm standard errors of (RT-ST) and (ST-AT) thermal gradients as affected by shearing and time points.

\begin{tabular}{lllll}
\hline & & $8: 00 \mathrm{am}$ & $2: 00 \mathrm{pm}$ & Overall \\
\hline \multirow{3}{*}{ RT-ST $\left({ }^{\circ} \mathrm{C}\right)$} & Unshorn & $2.92 \pm 0.156^{\mathrm{a}}$ & $1.57 \pm 0.162^{\mathrm{b}}$ & $2.27 \pm 0.131$ \\
& Shorn & $3.17 \pm 0.161^{\mathrm{a}}$ & $1.17 \pm 0.155^{\mathrm{b}}$ & $2.14 \pm 0.130$ \\
& Overall & $3.04 \pm 0.112^{\mathrm{a}}$ & $1.36 \pm 0.112^{\mathrm{b}}$ & \\
\hline \multirow{3}{*}{ ST-AT $\left({ }^{\circ} \mathrm{C}\right)$} & Unshorn & $19.99 \pm 0.502^{\mathrm{a}}$ & $9.57 \pm 0.521^{\mathrm{b}}$ & $14.97 \pm 0.531$ \\
& Shorn & $18.99 \pm 0.518^{\mathrm{a}}$ & $9.75 \pm 0.499^{\mathrm{b}}$ & $14.20 \pm 0.527$ \\
& Overall & $19.50 \pm 0.360^{\mathrm{a}}$ & $9.66 \pm 0.306^{\mathrm{b}}$ & \\
& &
\end{tabular}

Means with different lowercase superscripts in the same row differ significantly $(\mathrm{P}<0.05)$.
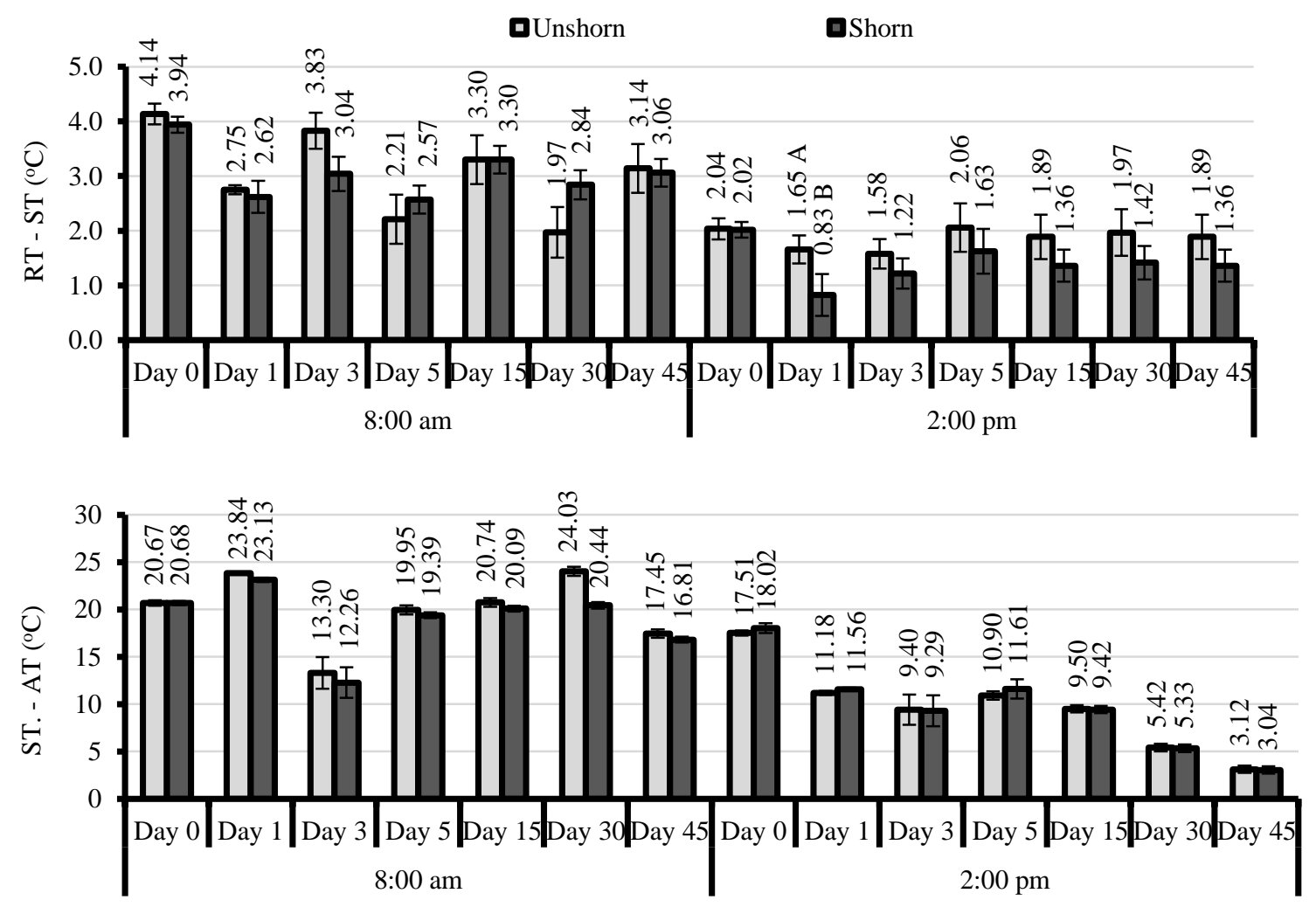

Fig.5: (RT-ST) and (ST-AT) thermal gradients of the experimental groups at 8:00 am and 2:00 pm time points throughout the experiment.

\section{REFERENCES}

[1] Abdel Khalek, T. M. M. (2007). Thermoregulatory responses of sheep to starvation and heat stress conditions. Egypt. J. Anim. Prod. 44 (2): 137-150.

[2] Aleksiev, Y. (2007). Effects of time of shearing on growth rate and some physiological responses in fine wool of two tooth sheep. Bio. Tech. Anim. Husbandry. 23 (6):179:189.
[3] Aleksiev, Y. (2008). Effect of shearing on some physiological responses in lactating ewes kept indoor. Bulg. J. Agric. Sci., 14 (4): 417-423.

[4] Aleksiev, Y. (2009). The effect of shearing on the behaviour of some physiological responses in lactating Pleven Blackhead ewes. Bulg. J. Agric. Sci., 15 (5): 446452.

[5] Al-Ramamneh, D., Gerken, D. and Riek, A. (2011). Effect of shearing on water turnover and thermobiological 
variables in German Blackhead mutton sheep. Journal of animal science, 89: 4294-4304.

[6] Avondo, M., Bordonaro, S., Marletta, D., Guastella, A. and d'Urso, G. (2000). Effects of shearing and supplemental level on intake of dry ewes grazing on barley stubble. Small Ruminant Research, 38: 237-241.

[7] Cabanac, M. (2006). Adjustable set point to honor Harrold T. Hammel. J. App. Physiol. 109 1338-1346.

[8] Casella, S., Giudice, E., Passantino, A., Zumbo, A., Di Pietro, S. and Piccione, G. (2016). Shearing induces secondary biomarkers responses of thermal stress in sheep. Animal Science Papers and Reports, 34: 73-80.

[9] Diesel, D; Tucker, A. and Robertshaw, D. (1990). Coldinduced changes in breeding pattern as a strategy to reduce respiratory heat loss. J. Appl. Physiol. 69:1946:1952

[10] Dikmen, S., Orman, A. and Ustuner, H. (2011). The effect of shearing in a hot environment on some welfare indicators in Awassi lambs. Tropical animal health and production, 43: 1327-1335.

[11] Fazio, E; Medica, P; Cravana, C. and Ferlazzo, A. (2016). Effects of previous experience on total blood and free iodothyronin responses to isolation, restraint and shearing in sheep (Ovis aries). Veterinarni Medicana. 61 (16): $65-$ 71.

[12] Hales, J. R. S; Bennett, J. W. and Fawcett, A. A. (1976). Effects of acute cold exposure on the destination of cardiac output in the sheep. Euro. J. Physiol. 366: 153157.

[13] Hristov, S., Maksimović, N., Stanković, B., Žujović, M., Pantelić, V., Stanišić, N. and Zlatanović, Z. (2012). The most significant stressors in intensive sheep production. Biotechnology in Animal Husbandry, 28: 649-658.

[14] Kadzere, C.T; Murphy, M. R; Siliankov, N. and Maitz, E. (2002). The effect of shearing in lactating Dairy cows: a review. Livestock. Prod. Sci. 77: 59-91.

[15] Kubnen, G. and Jesssen, C. (1988). The metabolic responses to skin temperature. Pflugers Arch. 412:402408.

[16] Lowe, T. C; Ingram, C. J. and Harris, P. (2001). Impact of climate on thermal rhythm in pastoral sheep. Physiol. Behav. 74: 659-664.

[17] Mclean, N.J; Craig, H. I. B; Fennessy, P. F; Behrent, M. J; Kersalake, J. I. and Campbell, A. W. (2015). Effect of Shearing on lamb growth and carcase performance. Proc. N. Z. Soc. Anim. Prod. 75:315:318.

[18] Mortola, J. P. and Frappell (2000). Ventilator response to changes in temperature in mammals and other vertebrates. Annual Rev. Physiol. 62: 847-874.

[19] Muslemipur, F. and Golzar-Adapi, S. (2016). Physiological and growth parameters of fattening lambs after shearing under heat-stress conditions. Anim. Prod Sci. 57(3): 569-575.

[20] Pennisi, P., Costa, A., Biondi, L., Avondo, M. and Piccione, G. (2004). Influence of the fleece on thermal homeostasis and on body condition in Comisana ewe lambs. Animal Research, 53: 13-19.

[21] Piccione, G. and Caola, G. (2003). Influence of shearing on the circadian rhythm of body temperature in the sheep. Journal of Veterinary Medicine Series A, 50: 235-240.

[22] Piccione, G., Lutri, L., Casella, S., Ferrantelli, V. and Pennisi, P. (2008). Effect of shearing and environmental conditions on physiological mechanisms in ewes. Journal of environmental biology, 29: 877-880.

[23] Piccione, G; Caola, G. and Refinetti, R. (2002). Effect of shearing on the core body temperature of three breeds of Miditerranean sheep, Small Ruminant Res. 46: 211-215.

[24] Revel, D.K; Main, S. F; Breier, B. H; Cottam, Y.H; Hennies, M. and McCutcheon, S. N. (2000). Metabolic responses to mid preganancy shearing that are associated with a selective increase in the birth weight in twin lambs. Domest. Anim.Endocrinology. 18 (4): 409-422.

[25] Steel, R. and Torrie, J. (1980). Principles and Procedures of Statistics. A Biometrical Approach, Me-Graw Hill Book Co., Inc., NY, USA

[26] Suhair, S. M. and Abdela, M. A. (2013) Effects of seasonal changes and shearing on thermoregulation, blood constituents and semen characteristics of desert rams (Ovis aries). Pak. J. Bio. Sci. 16 (24): 1884-1893.

[27] Taha, E.A; Abdel-Khalek, A.E.; Khalil , W.A. and Nahla, R.M. Abdel Aal. (2018). Wool Production and Characteristics, Physiological and Haematological Parameters and Level of some Metabolic Hormones in Barki Ewes Shorn in Autumn as Alternative of Spring Shearing. J. Anim. Poultry Prod., Mansoura Univ. 9 (10):415 - 422,

[28] Turnpenny, J. R; Wthes, C. M; Clark, J. A and McArthur, A. J. (2000). Thermal balance of livestock: II Applications ofparsimonious model. Agric. Meteorology. 101:29-52. 